\title{
A New Method of Relating Size of Spawning Gravel to Salmonid Embryo Survival
}

\author{
PAUL D. TAPPEL ${ }^{1}$ AND TED C. BJORNN \\ Idaho Cooperative Fishery Research Unit. University of Idaho, Moscow, Idaho 83843
}

\begin{abstract}
A new method for describing the size composition of salmonid spawning gravel was developed. For gravel samples from Idaho and Washington streams, cumulative distributions of particle sizes for gravel smaller than $25.4 \mathbf{~ m m}$ were consistently plotted as straight lines on log-probability paper. Because of the lognormal distribution of the particle sizes in this range, the size composition of material smaller than $25.4 \mathrm{~mm}$ was closely approximated by two points on a regression of cumulative particle size distribu tion. The two size classes that best reflected the composition of the spawning gravel size were the percentage of the substrate smaller than $9.50 \mathrm{~mm}$ and the percentage smaller than $0.85 \mathrm{~mm}$. Salmonid embryo survival was related to these two groups of particle size in laboratory tests. In these tests, $90-93 \%$ of the variability in embryo survival was correlated with changes in substrate size composition. Equations were developed to describe the effect of spawning gravel size composition on chinook salmon (Oncorhynchus tshawytscha) and steelhead (Salrno gaindneri) survival to emergence in a wide range of spawning gravel mixtures.

Gravel mixtures containing high percentages of fine sediment produced slightly smaller steelhead fry than gravels containing low percentages of fine sediment, but the difference was not significant $(P=$ 0.05). There was no relationship between changes in gravel size composition and the size of chinook salmon emergents. In gravels containing large amounts of fine sediment, many of the steelhead and chinook salmon fry emerged before yolk sac absorption was complete.
\end{abstract}

The detrimental effects of fine sediment on salmonid embryo survival have been intensively studied, but there is little agreement on which panicle size classes should be classified as fine sediment. Depending on the study, embryo survival has been negatively correlated with fine sediment of various sizes: $<0.85 \mathrm{~mm}, 1-3 \mathrm{~mm},<3.3 \mathrm{~mm}$, and $<6.35 \mathrm{~mm}$. This nebulous definition of "fine" material has made it difficult for fisheries biologists to evaluate the quality of spawning areas based on gravel size composition. In this paper, fine sediment refers to sediment panicles that are predominantly silt and sand but may be as large as $12.7 \mathrm{~mm}$.

In gravels containing excessive amounts of fine sediment, most studies cited by Cordone and Kelley (1961), Gibbons and Salo (1973), and Iwamotoetal. (1978) attributed low embryo survival to decreased gravel permeability and/or entrapment of alevins and fry. Reduced permeability restricts the flow of water around incubating salmonid embryos. This results in a decreased supply of oxygen to the embryos and also allows accumulation of toxic metabolic wastes (free carbon dioxide and ammonia). Entombment of

1 Present address: U.S. Forest Service, Federal Building, Ketchikan, Alaska 99901. embryos and alevins occurs when fine material lodged in gravel interstices prevents their emergence. Cooper (1965) suggested that embryos could be crushed when the weight of overlaying material was transferred to the embryos via fine material.

McNeil and Ahnell (1964) were among the first to compare a specific size class of sediment to salmonid embryo survival. In pink salmon (Oncorhynchus gorbuscha) spawning areas of Alaska, they found that fry emergence was inversely related to the percentage of the spawning substrate that was smaller than $0.833 \mathrm{~mm}$ in diameter. Koski (1966) found that coho salmon (Oncorhynchus kisutch) embryos survived best in stream channels that contained small percentages of material less than $3.3 \mathrm{~mm}$ in diameter. Bjomn (1969) demonstrated that emergence of chinook salmon and steelhead fry was impeded by a large percentage of material finer than $6.35 \mathrm{~mm}$. In laboratory tests, Hall and Lantz (1969) found a significant inverse relationship between the amount of fine sediment $(1-3 \mathrm{~mm})$ and the ability of coho salmon and steelhead fry to emerge. Koski (1975) observed that cenain 


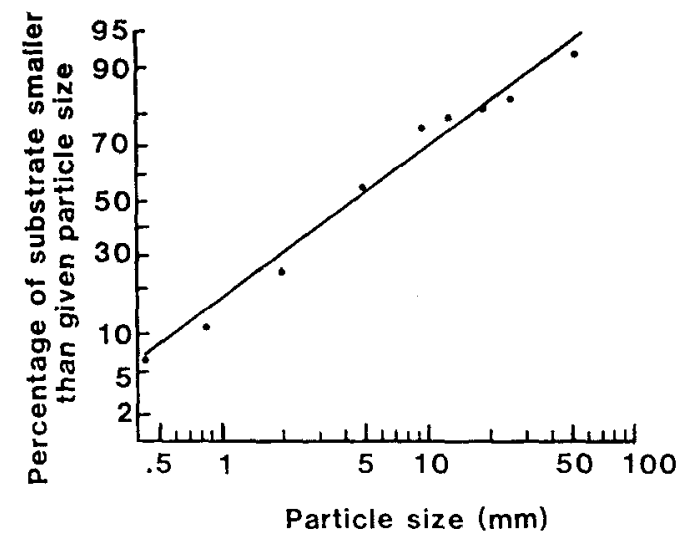

Figure 1. Log-probability plot of spawning gravel sample with a particle size distribution close to lognormal $\left(r^{2}=0.99\right)$.

amounts of fine sediment $0.105-3.327 \mathrm{~mm}$ in diameter decreased survival to emergence of chum salmon (Oncorhynchiis keta). Tagart (1976) reported that survival of coho salmon to emergence in natural redds decreased when more than $20 \%$ of the substrate was composed of particles finer than $0.85 \mathrm{~mm}$. Cederholmetal. (1981) determined that material finer than $0.85 \mathrm{~mm}$ was the most detrimental panicle size class for coho salmon embryo survival in the Clearwater River system, Washington.

Many workers use the concept of "percent fines" as a measure of the quality of spawning gravel. An inescapable problem with this measure is the determination of which particular particle size classes are harmful to incubating salmonid embryos. Salmonid mortality during incubation and alevin emergence depends on the total size range of the spawning substrate, not just the amount of substrate finer than a certain size. Also, different salmonid species probably can tolerate different levels of fine sediment, depending on embryo size and inherited adaptations to substrate conditions. "Percent fines" is an inadequate measure of spawning gravel quality.

Plaits et al. (1979) suggested the "geometric mean" particle diameter (Dg) as a companion measurement to "percent fines." Geometric means are computed as:

$$
\mathrm{D}_{\mathrm{g}}=\sqrt{\mathrm{D}_{84} \mathrm{D}_{16}}
$$

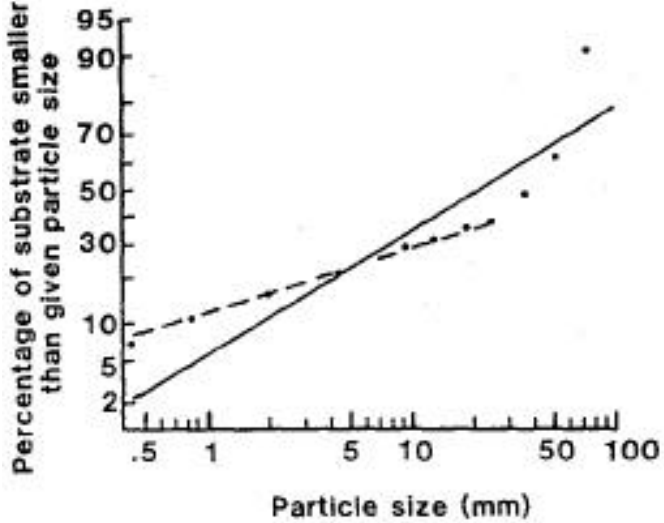

Figure 2. Typical deviation from lognormal particle distribution in spawning gravels from the South Fork Salmon River, particularly in upper end (right side) of the cumulative distribution plot. Solid line is for all particle sizes $\left(\mathbf{r}^{2}=0.89\right)$; broken line is for material smaller than $25.4 \mathrm{~mm}$ in diameter $\left(r^{2}=0.97\right)$.

where

$\mathrm{D}_{84}=$ a particle size of which $84 \%$ of the substrate is smaller.

$D_{16}=$ a particle size of which $16 \%$ of the substrate is smaller.

They proposed the use of $D_{g}$ primarily because (1) $\mathrm{D}_{\mathrm{g}}$ is commonly used in other disciplines to describe the composition of substrate sizes; (2) Dg describes stream substrate size composition better than "percent fines"; and (3) a statistical comparison of spawning areas is easier when using Dg instead of "percent fines."

In this paper, we present a new way of describing the size composition of slmonid spawning gravel that provides a more reliable, useful, and comprehensive measure of spawning gravel quality than "percent fines" or geometric mean. Two terms need to be denned. Spawning gravel refers to the total mixture of sediment sizes in the spawning substrate and is not limited to any particle size range. Survival to emergence is the percent survival of salmonid embryos from the time they are placed in the gravel until they emerge from the substrate as alevins or fry.

LOGNORMAL PARTICLE SIZE

DISTRIBUTION OF SPAWNING GRAVEL

Stream substrate size composition can be described by plotting the cumulative distribution 


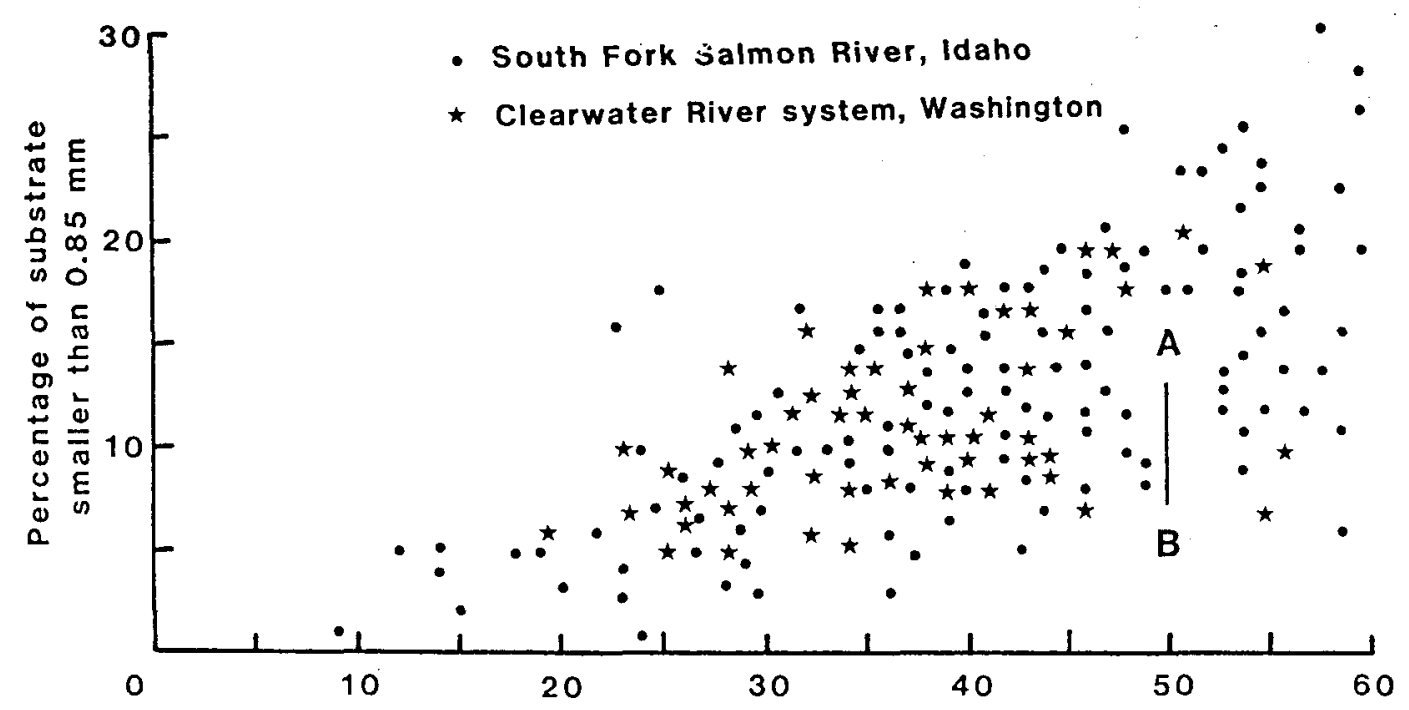

Percentage of substrate smaller than $9.50 \mathrm{~mm}$

Figure 3. Range of spawning gravel sizes for samples from two river systems. Line AB represents mixtures with the same "percent fines" $(50 \%$ smaller than $9.50 \mathrm{~mm})$ and geometric mean but different size compositions.

of sediment particle sizes on log-probability paper (Fig. 1). Geologists and hydraulic engineers frequently assume that the cumulative distribution of natural stream sediments will approximate a straight line on log-probability paper (Shen 1971). Sediment represented by a straight line on log-probability paper has a lognormal distribution of the panicle sizes.

By plotting sediment data on log-probability paper, Shirazi and Seim (1979) found that samples of spawning gravel from Oregon and Washington had particle size distributions close to log-normal. For 100 samples, they obtained an average coefficient of determination $\left(r^{2}\right)$ of 0.93 for the least squares regression lines through the data. We did a similar analysis with 100 samples of spawning gravel from the South Fork Salmon River in Idaho. All samples were collected by U.S. Forest Service personnel from salmon spawning areas. For these data, $r^{2}$ values averaged 0.95 and ranged from 0.62 to 1.00 .

Spawning gravel sizes could be completely and accurately described by regression equations if the entire range of panicle sizes in the substrate samples were consistently linear when plotted on logprobability paper. However, some sediment samples from the South Fork Salmon River had substantial deviations from lognormality and were not accurately represented by the regression equations.

Generally, sediment samples with substantial deviations from lognormality curved upwards in the upper end of cumulative distribution plots (Fig. 2). The solid line in Fig. 2 represents the linear regression through all data points with the $r^{2}$ value being 0.89. By ignoring material larger than 25.4 $\mathrm{mm}$ in diameter, a linear regression line with an $r^{2}$ value of 0.97 was obtained (dashed line. Fig. 2).

The average $r^{2}$ value for the 100 South Fork Salmon River samples increased slightly from 0.95 to 0.97 when material larger than $25.4 \mathrm{~mm}$ was not included in the analysis. In almost all samples, a straight line on log-probability paper accurately represented the material less than $25.4 \mathrm{~mm}\left(r^{2}=\right.$ $0.97)$. Only three samples had $r^{2}$ values less than 0.90 .

Data from 126 salmon spawning areas sampled by Cederholm et al. (1977) in the Clearwater River system in Washington were similarly analyzed. For these data, straight lines on log-probability paper closely approximated the composition of material 


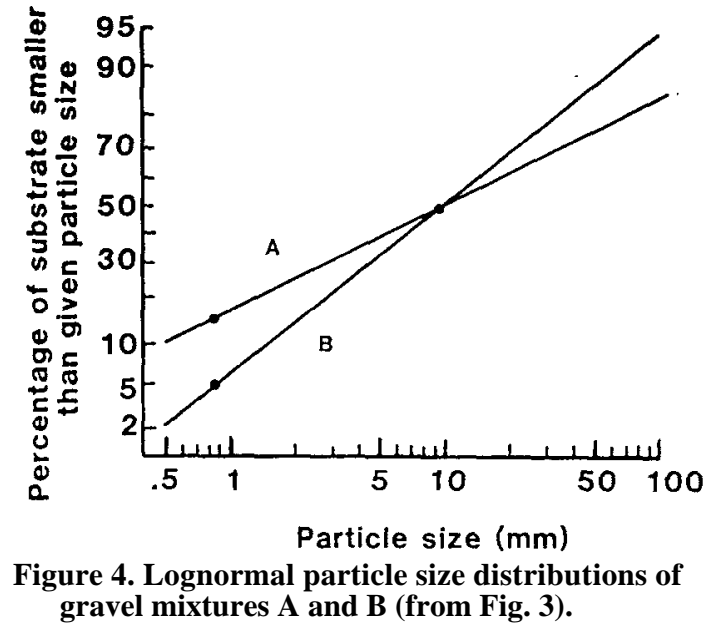

finer than $26.9 \mathrm{~mm}$. The average $r^{2}$ value for these samples was 0.97 and ranged from 0.85 to 1.00 .

\section{PROPOSED METHOD OF DESCRIBING SEDIMENT SIZE COMPOSITION}

Because the size composition of spawning gravel less than $25.4 \mathrm{~mm}$ can be accurately described by straight lines on log-probability paper, regression equations can be used to describe gravel size composition in this particle range. The regression equation is:

where

PERCENT $=\mathrm{C}+\mathrm{K} \cdot \log _{\mathrm{e}} \mathrm{SIZE}$

PERCENT $=$ inverse probability transformation of percentage of substrate smaller than a given sieve size,

$\mathrm{C}=$ intercept of regression line,

$\mathrm{K}=$ coefficient of variable $\log _{\mathrm{e}} \mathrm{SIZE}$,

$\mathrm{SIZE}=$ sieve size in millimeters.

Rather than determine regression equations for sediment samples, the description of spawning gravel composition was simplified with an approximation. Because of the linear distribution of particles less than $25.4 \mathrm{~mm} \mathrm{(} r^{2}$ values close to 1.0$)$, lines passing through data points for two sieve sizes closely approximate lines determined by the least squares regression procedure.

For data from the South Fork Salmon River, a line passing through data points for the $9.50 \mathrm{~mm}$ and 0.85 $\mathrm{mm}$ particle sizes closely approximated the line calculated by the least squares procedure for material smaller than $25.4 \mathrm{~mm}$. For the gravel sample presented in Fig. 2, the least squares regression line for material less than $25.4 \mathrm{~mm}$ was almost identical to the line drawn between $9.50 \mathrm{~mm}$ and $0.85 \mathrm{~mm}$ data points.

Using an analysis of residuals, we found that the lines that extended through the $9.50 \mathrm{~mm}$ and 0.85 $\mathrm{mm}$ data points consistently overestimated the amount of material smaller than $0.25 \mathrm{~mm}$. However, this particle size class rarely comprised more than $5 \%$ of the substrate in the samples we analyzed (usually $1-2 \%$ ), so that a small overestimate should not invalidate the technique.

\section{APPLICATION OF PROPOSED METHOD}

The size range of spawning substrate from two river systems was graphically illustrated by plotting the percentage of particles smaller than $9.50 \mathrm{~mm}$ vs. the percentage less than $0.85 \mathrm{~mm}$. Each point in Fig. 3 represents one sample of spawning gravel from the South Fork Salmon River or the Clearwater River. Points A and B (Fig. 3) represent two different spawning gravel samples. The vertical line passing through A and B represents a continuum of gravel size compositions, all with $50 \%$ of the substrate less than $9.50 \mathrm{~mm}$ in diameter. If particles less than 9.50 $\mathrm{mm}$ are considered "fines," then any data points falling on the line $\mathrm{AB}$ would represent samples of spawning gravel with the same "percent fines" but different particle size distributions.

If the samples represented by points A and B (Fig. 3) had lognormal particle size distributions (Fig. 4), the geometric mean of both mixtures would be equal:

For A:

$$
\begin{aligned}
& D_{g}=\sqrt{D_{84} D_{16},} \quad D_{84}=95 \mathrm{~mm} \\
& D_{g}=\sqrt{(95)(.95)}, \quad D_{16}=0.95 \mathrm{~mm} \\
& D_{g}=9.50 \mathrm{~mm}
\end{aligned}
$$

For B:

$$
\begin{aligned}
& \mathrm{D}_{\mathrm{g}}=\mathrm{V} \overline{\mathrm{D}_{84} \mathrm{D}_{16}}, \quad \mathrm{D}_{84}=41 \mathrm{~mm} \\
& \mathrm{D}_{\mathrm{g}}=\mathrm{V} \overline{(41)(2.2)}, \quad \mathrm{D}_{16}=2.2 \mathrm{~mm} \\
& \mathrm{D}_{\mathrm{g}}=9.50 \mathrm{~mm} .
\end{aligned}
$$

In the past, researchers relating salmonid embryo survival to $\mathrm{D}_{\mathrm{g}}$ or "percent fines" would have considered samples $\mathrm{A}$ and $\mathrm{B}$ to be identical. However, as shown in Fig. 4, samples A and B would have different particle size distributions, 
Table 1. Size composition of gravel mixtures used in steelhead and chinook salmon embryo survival tests, expressed as percentages of each gravel mixture smaller than certain particle sizes.

\begin{tabular}{|c|c|c|c|c|c|c|c|c|c|c|}
\hline \multirow{2}{*}{$\begin{array}{l}\text { Gravel } \\
\text { mixture }\end{array}$} & \multicolumn{9}{|c|}{ Particle size $(\mathrm{mm})$} & \multirow{2}{*}{$\begin{array}{l}\text { Geometric } \\
\text { mean }(\mathrm{mm})\end{array}$} \\
\hline & 50.8 & 25.4 & 12.7 & 9.50 & 6.35 & 4.76 & 1.70 & 0.85 & 0.42 & \\
\hline $0: 0$ & 99.4 & 73.7 & 4.2 & 0 & 0 & 0 & 0 & 0 & 0 & 21.5 \\
\hline $10: 4$ & 99.5 & 76.3 & 13.8 & 10.0 & 9.9 & 9.4 & 5.9 & 3.9 & 2.2 & 19.1 \\
\hline $20: 8$ & 99.5 & 79.0 & 23.4 & 20.0 & 19.8 & 18.7 & 11.7 & 7.8 & 4.4 & 11.8 \\
\hline $30: 12$ & 99.6 & 81.6 & 32.9 & 30.0 & 29.6 & 28.1 & 17.6 & 11.7 & 6.6 & 6.6 \\
\hline $40: 16$ & 99.6 & 84.2 & 42.5 & 40.0 & 39.5 & 37.5 & 23.4 & 15.6 & 8.8 & 4.7 \\
\hline $50: 20$ & 99.7 & 86.8 & 52.1 & 50.0 & 49.4 & 46.8 & 29.3 & 19.5 & 11.0 & 4.0 \\
\hline $15: 4$ & 99.5 & 77.6 & 18.6 & 15.0 & 14.1 & 12.2 & 5.7 & 3.5 & 2.0 & 16.4 \\
\hline $25: 6$ & 99.6 & 80.3 & 28.2 & 25.0 & 23.4 & 20.3 & 9.5 & 5.8 & 3.4 & 10.4 \\
\hline $35: 8$ & 99.6 & 82.9 & 37.7 & 35.0 & 32.8 & 28.4 & 13.3 & 8.2 & 4.8 & 7.6 \\
\hline $45: 10$ & 99.7 & 85.5 & 47.3 & 45.0 & 42.2 & 36.5 & 17,1 & 10.5 & 6.2 & 6.1 \\
\hline $55: 13$ & 99.7 & 88.2 & 56.9 & 55.0 & 51.6 & 44.7 & 20.9 & 12.9 & 7.5 & 5.0 \\
\hline $10: 1$ & 99.5 & 76.3 & 13.8 & 10.0 & 9.0 & 7.1 & 1.8 & 0.7 & 0.4 & 19.1 \\
\hline $20: 1$ & 99.5 & 79.0 & 23.4 & 20.0 & 18.0 & 14.2 & 3.5 & 1.4 & 0.9 & 13.9 \\
\hline $30: 2$ & 99.6 & 81.6 & 32.9 & 30.0 & 26.9 & 21.3 & 5.2 & 2.0 & 1.3 & 10.7 \\
\hline $40: 3$ & 99.6 & 84.2 & 42.5 & 40.0 & 35.9 & 28.4 & 7.0 & 2.7 & 1.7 & 9.1 \\
\hline
\end{tabular}

implying that embryo survival could differ in the two mixtures.

By using gravel mixtures similar to those found in streams, salmonid embryo survival could be implicitly related to the entire range of material less than $25.4 \mathrm{~mm}$. This relationship could be evaluated by comparing embryo survival to two substrate variables (percentage of the substrate smaller than $9.50 \mathrm{~mm}$ and percentage less than $0.85 \mathrm{~mm}$ ). This technique would eliminate the need to define exactly which particle sizes are detrimental to salmonid embryos, and it only requires the assumption that gravel material larger than $25.4 \mathrm{~mm}$ is not harmful to incubating salmonids.

\section{LABORATORY TESTS}

Laboratory tests were designed to correlate salmonid embryo survival with mixtures of sediment sizes like those found in stream spawning areas. A large amount of granitic streambed sediment from an alluvial deposit in central Idaho was transported to the University of Idaho where material larger than $12.7 \mathrm{~mm}$ was removed by sieving. The remaining material was sluiced, sorted into size groups, and then combined with $12.7-76.1 \mathrm{~mm}$ gravel to provide a range of gravel mixtures for embryo incubation tests (Table 1).

Each experimental gravel mixture was given a label corresponding to the percentage of gravel smaller than $9.50 \mathrm{~mm}$ and the percentage smaller than $0.85 \mathrm{~mm}$ (Table 1). As an example, for the gravel mixture labeled 30:2, 30\% of the mixture was smaller than $9.50 \mathrm{~mm}$ in diameter and $2 \%$ was smaller than $0.85 \mathrm{~mm}$. The labels do not include fractions because all percentages were rounded to the nearest whole number.

The gravel mixtures were plotted according to the size composition of each gravel mixture (Fig. 5). The shaded area delineates the range of gravel size compositions found in salmon spawning areas in the Clearwater River, Washington, and the South Fork Salmon River, Idaho (Fig. 3). As shown in Fig. 5, the range of experimental gravel mixtures was similar to the range of gravel composition found in these two rivers.

Because of the way the experimental gravel mixtures were produced, they did not exactly duplicate natural mixtures. Each experimental mixture contained more material from 12.7 to 25.4 $\mathrm{mm}$ than its natural counterpart. This deviation would be significant if the $12.7-25.4 \mathrm{~mm}$ material was detrimental to incubating salmonid embryos. However, we found no evidence in the literature that this size range was harmful to salmonid embryos, and we assumed this deviation from natural gravel sizes would not substantially affect our experimental results.

Experimental gravel mixtures were put into 40 incubation troughs at the University of Idaho (Fig. 6 ). There were either two or three replicates for each of the 15 gravel mixtures. Water flow and gradient through each trough could be regulated by a valve at the inlet (Fig. 6).

Water-hardened steelhead embryos from Dworshak National Fish Hatchery (Idaho) were 


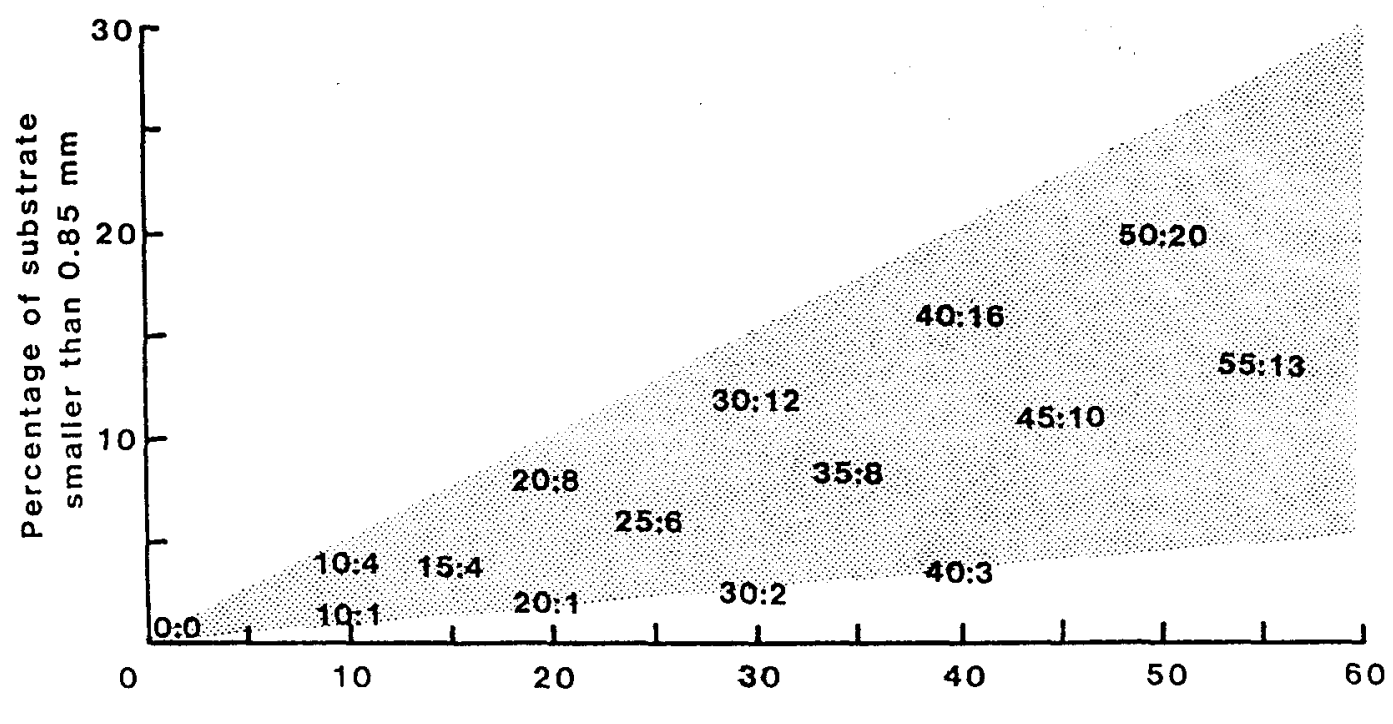

Percentage of substrate smaller than $9.50 \mathrm{~mm}$

Figure 5. Experimental gravel mixtures overlying range of natural spawning substrate. Assignment of labels $(0: 0,20: 8$, etc. $)$ corresponds to respective experimental gravel compositions.

counted into Vibert boxes that had been filled with appropriate gravel mixtures. Each box received 50 embryos. Four Vibert boxes were placed in each incubation trough and buried to a depth of $15-20 \mathrm{~cm}$. Care was taken to surround the 200 embryos in each trough with a homogeneous mixture of gravel. Vibert box lids were left open so that emerging fry would not be impeded by the plastic mesh (Fig. 6).

Chilled, unchlorinated water flowing through each trough kept water temperatures between 10 and 13 C. Throughout the experiment, dissolved oxygen levels remained near saturation. Before the embryos hatched, water levels were kept below the surface of the gravel (Fig. 6) so the gradient of water could be maintained at $2 \%$ in each incubation trough.

After 35 days of incubation, fry began to emerge and the water levels in each trough were raised above the gravel. Steelhead fry were collected over a 3 -week period as they emerged from each experimental gravel mixture. Survival in each incubation trough was measured by the number of fry collected. Fifty fry from each mixture were weighed to the nearest milligram on a Mettler balance, and fork lengths were recorded to the nearest millimeter.

A similar experiment was done with chinook salmon embryos. Because chinook salmon embryos are sensitive to handling before the "eyed" stage, "eyed" chinook salmon embryos were used in the experiments. These salmon embryos were incubated for 52 days in the Carson National Fish Hatchery (Washington) and had 624 temperature units (Leitritz and Lewis 1976) before

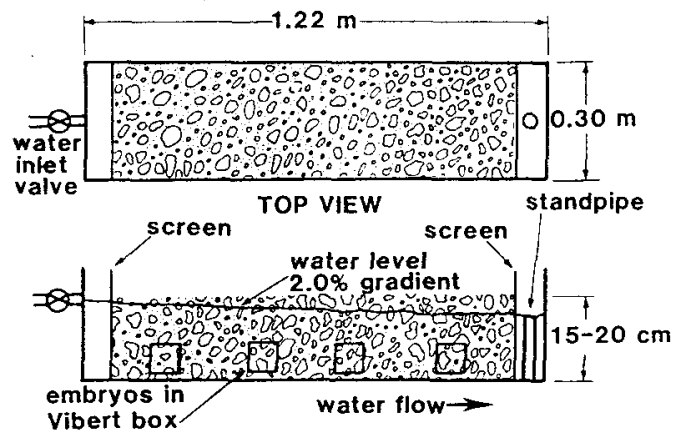

SIDE VIEW

Figure 6. Top and side views of an incubation trough used to evaluate steelhead and chinook salmon survival to emergence in various gravel mixtures. Side view shows incubation trough after placement of salmonid embryos and adjustment of water level. 
Table 2. Average survival to emergence of steelhead and chinook salmon embryos in experimental gravel mixtures.

\begin{tabular}{ccc}
\hline Gravel mixture & \multicolumn{2}{c}{$\begin{array}{c}\text { Average percent survival to } \\
\text { emergence (number of replicates) }\end{array}$} \\
\cline { 2 - 3 } & Steelhead & Chinook salmon \\
\hline $0: 0$ & $93(2)$ & $96(2)$ \\
$10: 4$ & $87(3)$ & $99(3)$ \\
$20: 8$ & $86(3)$ & $97(3)$ \\
$30: 1 ;$ & $59(3)$ & $88(3)$ \\
$40: 16$ & $14(3)$ & $32(3)$ \\
$50: 20$ & $10(3)$ & $6(3)$ \\
$15: 4$ & $92(3)$ & $95(3)$ \\
$25: 6$ & $91(3)$ & $93(3)$ \\
$35: 8$ & $67(3)$ & $77(3)$ \\
$45: 10$ & $59(3)$ & $61(3)$ \\
$55: 13$ & $30(2)$ & $18(3)$ \\
$10: 1$ & $94(2)$ & $95(2)$ \\
$20: 1$ & $93(2)$ & $92(2)$ \\
$30: 2$ & $95(2)$ & $88(2)$ \\
$40: 3$ & $90(2)$ & $87(2)$ \\
\hline
\end{tabular}

they were placed in our experimental incubation troughs.

Chinook salmon embryos were handled and placed in gravel mixtures exactly the same as the steelhead embryos, except that only 25 chinook salmon embryos were placed in each Vibert box. Each incubation trough contained 100 "eyed" chinook

Table 3. Observed values, equation predictions, and confidence intervals for steelhead embryo survival to emergence in gravel mixtures. Survival values are expressed as percentages.

\begin{tabular}{|c|c|c|c|c|c|c|}
\hline \multirow{3}{*}{$\begin{array}{c}\text { Gravel } \\
\text { mixture }\end{array}$} & \multirow{3}{*}{$\begin{array}{c}\mathrm{Ob}- \\
\text { served }\end{array}$} & \multirow{3}{*}{$\begin{array}{l}\text { Equa } \\
\text { tion } \\
\text { predi } \\
\text { ction }\end{array}$} & \multicolumn{4}{|c|}{ Confidence range } \\
\hline & & & \multicolumn{2}{|c|}{$95 \%$} & \multicolumn{2}{|c|}{$90 \%$} \\
\hline & & & low & high & low & high \\
\hline $0: 0$ & 93 & 95 & 74 & 115 & 78 & 112 \\
\hline $10: 4$ & 87 & 91 & 70 & 111 & 74 & 108 \\
\hline $20: 8$ & 86 & 79 & 59 & 100 & 62 & 96 \\
\hline $30: 12$ & 59 & 60 & 40 & 81 & 43 & 77 \\
\hline $40: 16$ & 14 & 33 & 12 & 54 & 16 & 50 \\
\hline $50: 20$ & 10 & -1 & -23 & 20 & -19 & 17 \\
\hline $15: 4$ & 92 & 90 & 70 & 111 & 73 & 107 \\
\hline $25: 6$ & 91 & 82 & 62 & 102 & 65 & 99 \\
\hline $35: 8$ & 67 & 70 & 50 & 90 & 53 & 87 \\
\hline $45: 10$ & 59 & 54 & 33 & 74 & 37 & 71 \\
\hline $55: 13$ & 30 & 33 & 11 & 55 & 15 & 51 \\
\hline $10: 1$ & 94 & 95 & 74 & 115 & 77 & 112 \\
\hline $20: 1$ & 93 & 94 & 74 & 115 & 77 & 111 \\
\hline $30: 2$ & 95 & 94 & 73 & 115 & 77 & 111 \\
\hline $40: 3$ & 90 & 93 & 71 & 115 & 75 & 111 \\
\hline
\end{tabular}

Table 4. Observed values, equation predictions, and confidence intervals for chinook salmon embryo survival to emergence in gravel mixtures. Survival values are expressed as percentages.

\begin{tabular}{|c|c|c|c|c|c|c|}
\hline \multirow{3}{*}{$\begin{array}{l}\text { Gravel } \\
\text { mixture }\end{array}$} & \multirow{3}{*}{$\begin{array}{c}\mathrm{Ob}- \\
\text { served }\end{array}$} & \multirow{3}{*}{$\begin{array}{l}\text { Equa- } \\
\text { tion- } \\
\text { predic } \\
\text { tion }\end{array}$} & \multicolumn{4}{|c|}{ Confidence range } \\
\hline & & & \multicolumn{2}{|c|}{$95 \%$} & \multicolumn{2}{|c|}{$90 \%$} \\
\hline & & & low & high & low & high \\
\hline $0: 0$ & 96 & 93 & 75 & 112 & 78 & 109 \\
\hline $10: 4$ & 99 & 102 & 84 & 120 & 87 & 117 \\
\hline $20: 8$ & 97 & 97 & 78 & 115 & 82 & 112 \\
\hline $30: 12$ & 88 & 78 & 60 & 97 & 63 & 94 \\
\hline $40: 16$ & 32 & 47 & 28 & 65 & 32 & 62 \\
\hline $50: 2$ & 6 & 2 & -17 & 21 & -14 & 18 \\
\hline $15: 4$ & 95 & 98 & 80 & 116 & 83 & 113 \\
\hline $25: 6$ & 93 & 91 & 73 & 109 & 76 & 106 \\
\hline $35: 8$ & 77 & 76 & 58 & 94 & 61 & 91 \\
\hline $45: 10$ & 61 & 53 & 35 & 71 & 38 & 68 \\
\hline $55: 13$ & 18 & 22 & 3 & 40 & 6 & 37 \\
\hline $10: 1$ & 95 & 95 & 77 & 113 & 80 & 110 \\
\hline $20: 1$ & 92 & 94 & 76 & 112 & 79 & 109 \\
\hline $30: 2$ & 88 & 91 & 73 & 109 & 76 & 106 \\
\hline $40: 3$ & 87 & 85 & 67 & 103 & 70 & 100 \\
\hline
\end{tabular}

salmon embryos. Thirty days of incubation at 10-13 $\mathrm{C}$ elapsed before fry emergence began. As with the steelhead experiment, water levels in ach trough were raised when fry were ready to emerge. Emerging fry were captured, counted, weighed, and measured.

Step-wise regression was used to develop the best second-order equations relating gravel size to steelhead and chinook salmon survival to emergence. Survival was correlated with two substrate variables: the percentage of the substrate smaller than $9.50 \mathrm{~mm}\left(\mathrm{~s}_{9.5}\right)$ and the percentage less than $0.85 \mathrm{~mm}\left(\mathrm{~s}_{0.85}\right)$. Second-order terms $\left(\mathrm{s}_{9.5}^{2}, \mathrm{~s}^{2}{ }_{0.85}\right)$ and a cross-product term $\left(\mathrm{s}_{9.5}, \mathrm{~s}_{0.85}\right)$ were included as variables in the regression analysis to detect curvilinear relationships between embryo survival and gravel size.

Average lengths and weights of the steelhead and chinook salmon fry were calculated for each experimental gravel mixture. A Duncan's multiple range lest was performed on each data set to detect significant relationships between fry size and size composition of the gravel.

\section{RESULTS}

\section{Embryo Survival}

Survival to emergence of steelhead and chinook salmon embryos ranged from 6 to $99 \%$ (Table 2). As the amount of fine material increased in the 


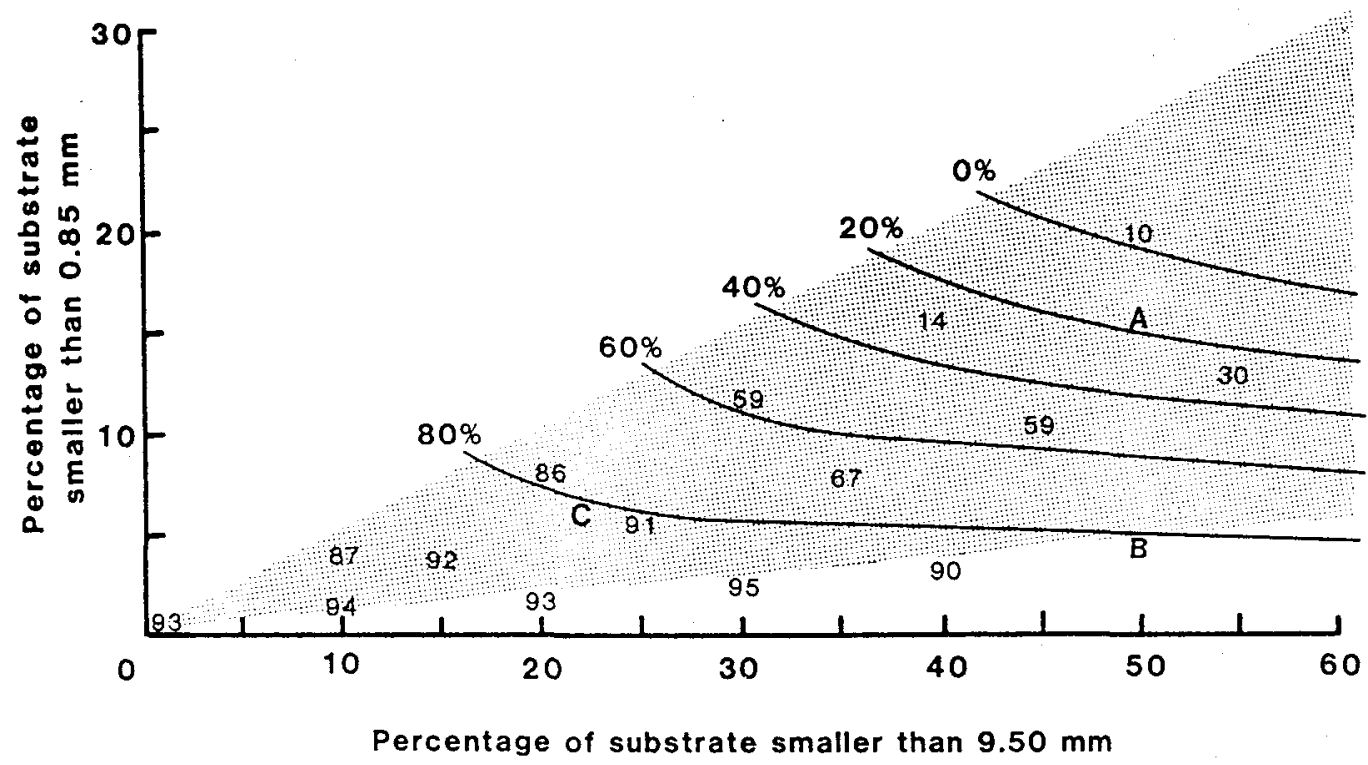

Figure 7. Isolines showing survival predictions $(80 \%, 60 \%, 40 \%, 20 \%, 0 \%)$ for steelhead embryos under various combinations of natural spawning gravel. Scattered numbers are percent survival values from laboratory tests.

experimental gravel mixtures, embryo survival of both species decreased.

The best second-order equation relating steelhead survival to gravel size composition was:

$$
\begin{aligned}
\text { Percent survival }= & 94.7-0.116 \mathrm{~s}^{2}{ }_{9.5}, \mathrm{~s}^{2}{ }_{0.85} \\
& +0.007 \mathrm{~s}^{2}{ }_{9.5}
\end{aligned}
$$

This equation had an $r^{2}$ value of 0.90 . For chinook salmon embryos, the best equation relating survival to gravel size composition was:

$$
\text { Percent survival }=93.4-0.171 \mathrm{~s}_{9.5}^{2}, \mathrm{~s}_{0.85}^{2}
$$

$$
+3.87 \mathrm{~s}_{0.85}^{2}
$$

This equation had an $r^{2}$ value of 0.93 .

These equations were used to predict seelhead and chinook salmon embryo survival for gravel mixtures like those used in the incubation experiments (Tables 3 and 4). Predicted survival values less than zero or greater than 100 were unrealistic and were interpreted as 0 or $100 \%$, respectively (Tables 3 and 4 ).

Using the above equations, embryo survival was predicted for a wide range of spawning substrates. "Three-dimensional" graphs help to visualize the relationship between gravel size composition and the equation-generated predictions for embryo survival (Fig. 7 and 8). Different gravel mixtures in which steelhead and chinook salmon survival would be similar are depicted by the lines in Fig. 7 and 8. For example, survival would be $80 \%$ in the two gravel mixtures corresponding to points B and C in Fig. 7.

Linear relationships between panicle size classes and steelhead survival to emergence were strongest for sizes smaller than $1.70 \mathrm{~mm}$ (Table 5). If steelhead embryo survival is related to a single particle size (e.g.. "percent fines"), $1.70 \mathrm{~mm}$ or smaller will provide the best relationship.

Particle size classes also were correlated with chinook salmon embryo survival using linear regressions (Table 5). If chinook salmon embryo survival is correlated with one size class, a particle size of $4.76 \mathrm{~mm}$ or smaller will provide the best relationship. Gravel material of $1.70-4.76 \mathrm{~mm}$ in diameter was more harmful to chinook salmon embryos than to steelhead.

Percent survival of steelhead and chinook salmon embryos also was compared to the geometric mean of each experimental gravel mixture (Fig. 9). The relationship between geometric mean and embryo survival was drawn by eye to best fit the experimental data (Fig. 9). We observed higher embryo survival rates than those compiled by Shirazi and Seim (1979). 


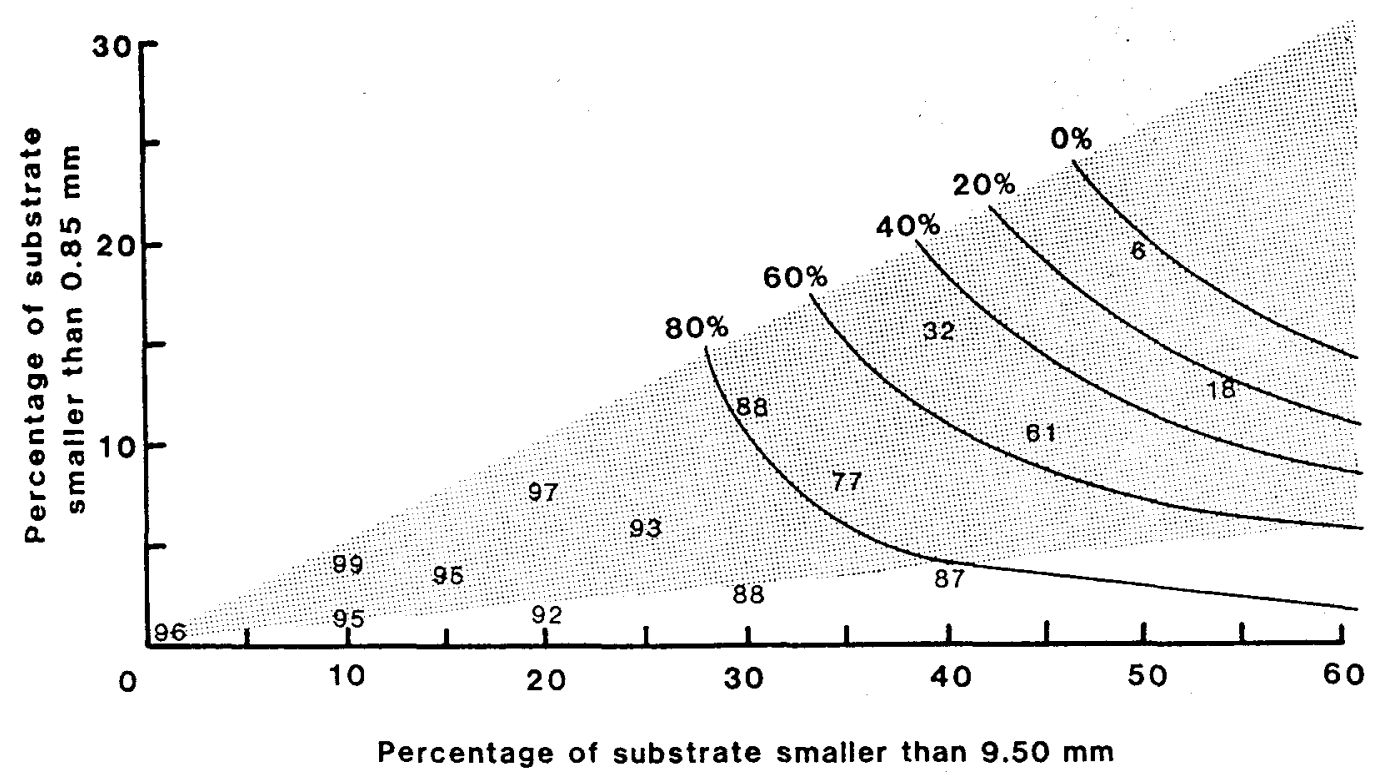

Figure 8. Isolines showing survival predictions $(80 \%, 60 \%, 40 \%, 20 \%, 0 \%)$ for chinook salmon embryos under various combinations of natural spawning gravel. Scattered numbers are percent survival values from laboratory tests.

\section{Size of Emergent Fry}

For the range of gravel mixtures tested, lengths and weights of emerging steelhead fry varied little. The smallest fry averaged only $0.8 \mathrm{~mm}$ (and $22 \mathrm{mg}$ ) smaller than the largest (Table 6). Although the trend was indistinct and not statistically significant $(P=$ 0.05), steelhead fry emerging from gravels with high percentages of fine material generally were smaller than fry from gravels containing low percentages of fine sediment (Table 6). Fry emerging from mixture 55: 13 weighed significantly less $(P<0.05)$ than all other steelhead fry (Table 6). There was no significant relationship between size of chinook salmon fry and gravel bed composition (Table 7).

\section{Timing of Fry Emergence}

In gravels with large proportions of fine material, steelhead and chinook salmon fry tended to emerge before yolk sac absorption was complete. In contrast, fry emerging from gravels with low percentages of fine sediment emerged only after total absorption of the yolk sac. These observations were not amenable for statistical analy sis.

\section{DISCUSSION}

For gravel mixtures in natural spawning areas, the size composition of material finer than $25.4 \mathrm{~mm}$ can consistently be approximated by straight lines when cumulative particle size distributions are plotted on log-probability paper. Knowing the percentage of the substrate smaller than $9.50 \mathrm{~mm}$ and the percentage smaller than $0.85 \mathrm{~mm}$, the size composition of material finer than $25.4 \mathrm{~mm}$ can be described accurately. By comparing steelhead and chinook salmon embryo survival to these two particle size groups, embryo survival was indirectly related to the entire range of material less than $25.4 \mathrm{~mm}$ in diameter. Spawning substrate material smaller than $25.4 \mathrm{~mm}$ includes all particle sizes that are potentially harmful to incubating salmonid embryos.

Comparisons of the isolines for steelhead (Fig. 7) and chinook salmon (Fig. 8) revealed how various particle sizes affected survival of steelhead and chinook salmon embryos. "Lines of equal survival" for steelhead were almost horizontal, implying that steelhead embryo survival was strongly related to substrate material less than $0.85 \mathrm{~mm}$ and only weakly related to the percentage of the substrate finer than $9.50 \mathrm{~mm}$. 
Table 5. Coefficients of determination for linear regressions of individual particle size classes on survival of steelhead and chinook salmon embryos.

\begin{tabular}{ccc}
\hline $\begin{array}{c}\text { Particle size class } \\
(\mathrm{mm})\end{array}$ & \multicolumn{2}{c}{$\mathrm{r}^{2}$ values } \\
\cline { 2 - 3 } & Steelhead & Chinook salmon \\
\hline 9.50 & 0.56 & 0.66 \\
6.35 & 0.62 & 0.70 \\
4.76 & 0.71 & 0.74 \\
1.70 & 0.86 & 0.74 \\
0.85 & 0.86 & 0.70 \\
0.42 & 0.86 & 0.71 \\
\hline aParticle size class is denned as the percentage of substrate smaller than a
\end{tabular}
given sieve size.

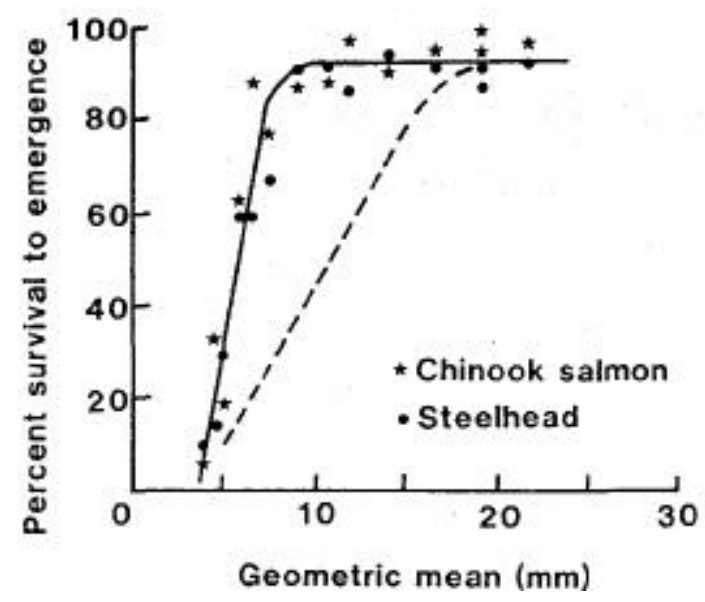

"Lines of equal survival" for chinook salmon embryos (Fig. 8) were neither vertical nor horizontal. Compared to steelhead, this demonstrated that survival of chinook salmon embryos was more strongly affected by material from 0.85 to $9.50 \mathrm{~mm}$ in diameter. Correlations of individual particle size classes and embryo survival (Table 5) indicated that material from 1.70 to $4.76 \mathrm{~mm}$ was more harmful to chinook salmon than steelhead embryos.

Compared to chinook salmon, the ability of steelhead to tolerate gravels with a finer particle size range was not surprising. In gravels with a high percentage of sand, Bjomn (1969) reported that steelhead fry emerged more readily than the larger chinook salmon fry. In a similar study, Hall and Lantz (1969) placed steelhead and coho salmon fry in various mixtures of sand and gravel and the steelhead were able to emerge through the restricted gravel interstices better than the larger coho salmon fry.

In most gravel mixtures tested, a higher percentage of the chinook salmon embryos survived than steelhead embryos (Table 2). The use of "eyed" chinook salmon embryos vs. newly fertilized steelhead embryos probably accounts for the higher survival of chinook salmon. Bjomn (1969) placed newly fertilized steelhead and chinook salmon embryos in gravel mixtures along with swim-up fry of both species. In almost all gravel mixtures tested, swim-up fry emerged at a higher rate than newly fertilized embryos.

If newly fertilized chinook salmon embryos had been used instead of "eyed" embryos in these experiments, survival probably would have been lower in most gravel mixtures and "equation" predictions for chinook salmon survival would
Figure 9. Relationship between geometric mean of each experimental gravel mixture and steelhead and chinook salmon embryo survival. Solid line fitted by eye to data from laboratory tests. Broken line represents survival curve presented by Shirazi and Seim (1979) for other data.

also have been lower. To relate gravel size to newly fertilized chinook salmon embryos instead of "eyed" embryos, the "lines of equal survival" in Fig. 8 should be shifted towards the origin. Unfortunately, we have no way to quantify such a shift.

Steelhead and chinook salmon embryos both had survival rates of approximately $90 \%$ when the geometric mean of the gravel mixtures exceeded 10 $\mathrm{mm}$. As the geometric means of gravel mixtures decreased below $10 \mathrm{~mm}$, percent survival decreased (Fig. 9). Using a number of studies, Shirazi and Seim (1979) showed that salmonid embryo survival was generally less than $90 \%$ unless the geometric mean exceeded $15 \mathrm{~mm}$. In gravels with identical geometric means, we observed higher survival rates than those reported by Shirazi and Seim (1979). As shown earlier, gravel mixtures can have different size compositions but the same geometric mean Therefore, the discrepancy between survival values presented here and those reported by Shirazi and Seim (1979) could result from differences in gravel composition. The usefulness of the geometric mean is limited because gravel mixtures with the same geometric mean can have different size compositions.

The effect of gravel size composition on the 
Table 6. Results of Duncan's multiple range test for steelhead lengths and weights. Means with the same grouping were not significantly different $(P=0.05)$.

\begin{tabular}{|c|c|c|c|c|c|}
\hline Gravel mixture & Mean length (mm) & & \multicolumn{3}{|c|}{ Grouping } \\
\hline $20: 1$ & 27.1 & A & & & \\
\hline $10: 1$ & 27.1 & A & & & \\
\hline $30: 2$ & 27.0 & A & & & \\
\hline 0:0 & 27.0 & A & & & \\
\hline $20: 8$ & 26.9 & A & B & & \\
\hline $25: 6$ & 26.9 & A & B & & \\
\hline $35: 8$ & 26.9 & A & B & & \\
\hline $10: 4$ & 26.9 & A & $\mathrm{B}$ & & \\
\hline $15: 4$ & 26.8 & A & $\mathrm{B}$ & & \\
\hline $45: 10$ & 26.7 & A & B & $\mathrm{C}$ & \\
\hline $40: 3$ & 26.6 & & $\mathrm{~B}$ & $\mathrm{C}$ & $\mathrm{D}$ \\
\hline $50: 20$ & 26.5 & & $\mathrm{~B}$ & $\mathrm{C}$ & $\mathrm{D}$ \\
\hline $30: 12$ & 26.4 & & & $\mathrm{C}$ & $\mathrm{D}$ \\
\hline $40: 16$ & 26.4 & & & $\mathrm{C}$ & $\mathrm{D}$ \\
\hline $55: 13$ & 26.3 & & & & $\mathrm{D}$ \\
\hline \multicolumn{6}{|c|}{$\begin{array}{c}\text { Mean weight } \\
(\mathrm{mg})\end{array}$} \\
\hline $20: 1$ & 215 & A & & & \\
\hline $25: 6$ & 214 & A & & & \\
\hline $10: 4$ & 211 & A & $\mathrm{B}$ & & \\
\hline $20: 8$ & 210 & A & $\mathrm{B}$ & & \\
\hline $40: 3$ & 210 & A & $\mathrm{B}$ & & \\
\hline $45: 10$ & 210 & A & $\mathrm{B}$ & & \\
\hline $30: 2$ & 208 & A & B & & \\
\hline 0:0 & 208 & A & B & & \\
\hline $35: 8$ & 208 & A & B & & \\
\hline $10: 1$ & 207 & A & B & & \\
\hline $15: 4$ & 206 & A & B & & \\
\hline $50: 20$ & 203 & & B & & \\
\hline $30: 12$ & 203 & & B & & \\
\hline $40: 16$ & 203 & & B & & \\
\hline $55: 13$ & 193 & & & $\mathrm{C}$ & \\
\hline
\end{tabular}

size of emergent fry was not clear. Steelhead fry emerging from gravels with low percentages of fine sediment were slightly larger than those from gravels containing high percentages of fine material. There was little variation in chinook salmon fry size throughout the range of experimental gravel mixtures.

Somewhat in contrast to these results, Phillips et al. (1975) found that coho salmon fry emerging from gravels with high percentages of sand were smaller than those from gravels with low percentages. In the same tests (Phillips et al. 1975), lengths of steelhead fry were similar in all gravel mixtures. Koski (1966) found that coho salmon fry size was inversely related to the amount of fine sediment in the substrate. In a later study, Koski (1975) reported that chum salmon fry from gravels with high percentages of sand were
Table 7. Results of Duncan's multiple range test for chinook salmon lengths and weights. Means with the same grouping were not significantly different $(P=0.05)$.

\begin{tabular}{|c|c|c|c|c|c|}
\hline Gravel mixture & Mean length (mm) & & \multicolumn{2}{|c|}{ Grouping } & \\
\hline $10: 4$ & 31.3 & A & & & \\
\hline $25: 6$ & 31.2 & A & B & & \\
\hline $10: 1$ & 31.0 & A & B & $\mathrm{C}$ & \\
\hline $35: 8$ & 31.0 & A & B & C & \\
\hline $20: 8$ & 31.0 & A & B & $\mathrm{C}$ & \\
\hline $30: 2$ & 30.9 & A & B & $\mathrm{C}$ & \\
\hline $30: 12$ & 30.9 & A & B & $\mathrm{C}$ & \\
\hline $15: 4$ & 30.8 & A & B & $\mathrm{C}$ & \\
\hline $40: 16$ & 30.8 & A & B & $\mathrm{C}$ & \\
\hline $50: 20$ & 30.8 & A & B & $\mathrm{C}$ & \\
\hline $0: 0$ & 30.8 & A & B & $\mathrm{C}$ & \\
\hline $40: 3$ & 30.7 & & B & $\mathrm{C}$ & D \\
\hline $20: 1$ & 30.6 & & B & $\mathrm{C}$ & D \\
\hline $55: 13$ & 30.5 & & & $\mathrm{C}$ & D \\
\hline \multirow[t]{3}{*}{$45: 10$} & 30.2 & & & & $\mathrm{D}$ \\
\hline & Mean weight & & & & \\
\hline & $(\mathrm{mg})$ & & & & \\
\hline $10: 4$ & 369 & A & & & \\
\hline $20: 8$ & 362 & A & B & & \\
\hline $35: 8$ & 358 & A & B & & \\
\hline $25: 6$ & 356 & A & B & & \\
\hline $30: 12$ & 355 & A & B & $\mathrm{C}$ & \\
\hline $30: 2$ & 352 & A & B & $\mathrm{C}$ & \\
\hline $10: 1$ & 351 & A & B & $\mathrm{C}$ & \\
\hline $0: 0$ & 348 & A & B & $\mathrm{C}$ & \\
\hline $40: 3$ & 345 & $\mathrm{~A}$ & B & $\mathrm{C}$ & \\
\hline $55: 13$ & 344 & A & B & $\mathrm{C}$ & \\
\hline $40: 16$ & 343 & A & B & $\mathrm{C}$ & \\
\hline $20: 1$ & 339 & & B & $\mathrm{C}$ & \\
\hline $15: 4$ & 338 & & B & $\mathrm{C}$ & \\
\hline $50: 20$ & 335 & & B & $\mathrm{C}$ & \\
\hline $45: 10$ & 328 & & & $\mathrm{C}$ & \\
\hline
\end{tabular}

up to $3.0 \mathrm{~mm}$ shorter than fry from gravels with low percentages of sand, but the relationship was not consistent.

The effect of fine sediment on size of emergent salmonid fry remains unresolved. Koski (1975) speculated that selective mortality of larger embryos and increased environmental stress could both result in reduced average fry size in gravels containing high percentages of fine sediment. Selective entombment of larger fry could occur because smaller fry would have a better chance of squirming through restricted gravel interstices during emergence. Koski (1975) also suggested that stress caused by fine sediment increased the metabolic rate of slmonid embryos, resulting in a loss of growth.

Whether or not excessive deposition of fine sediment in spawning gravel areas reduces salmonid 
fry size enough to affect later survival is unclear. Whenever fine sediment does substantially reduce fry size, smaller fry probably are at a disadvantage after emergence. Relatively small fry might experience higher mortality due to selective predation (Parker 1971) or competition with larger fry of the same or similar species.

In our tests, a large percentage of steelhead and chinook salmon fry emerged from gravels containing high percentages of fine sediment before yolk sac absorption was complete. Thus, deposition of excessive amounts of fine sediment in spawning gravels may result in embryo stress and cause a early emergence of salmonid embryos (Barns 1969). Fry that emerge prematurely would be more susceptible to predation than fully developed fry because the residual yolk sac would impair their swimming ability (Thomas et al. 1969;Koski 1975), and their relatively small size could increase predation (Parker 1971). In some species, a bright red or orange yolk sac probably makes premature fry particularly vulnerable to predation.

FISHERY MANAGEMENT APPLICATIONS

The most important outcome of our research was the development of a new method for quantifying the effects of substrate size composition on salmonid embryo survival. By considering two particle sizes (i.e.. $9.50 \mathrm{~mm}$ and $0.85 \mathrm{~mm}$ ), salmonid embryo survival was implicitly related to a range of particle sizes in natural gravel mixtures. This approach is much better than trying to isolate which of the particle sizes are harmful to incubating salmonid embryos.

Of secondary importance was the development of equations which related steelhead and chinook salmon embryo survival to size composition of the gravel. Because both equations were developed in a laboratory environment, predictions of embryo survival generated by the equations may be inaccurate when applied to field conditions. The experimental gravel mixtures contained only small amounts of organic material. In spawning areas where organic material is abundant, embryo survival probably would be lower than predicted by the equations. Because salmonids disturb the spawning substrate in the process of redd digging, the percentage of fine material in the substrate after egg deposition is usually less than the percentage of fine sediment before spawning. The equations presented do not account for the ability of salmonids to change the size composition of gravel in spawning areas or the re-deposition of fine sediment in redds. Thus, embryo survival in natural situations may be different than predicted by the equations.

Although embryo survival in streams may not exactly parallel "equation" predictions, the equations should provide a good index of relative changes in survival. As an example, suppose the steelhead equation predicted that embryo survival in a stream would decrease from 80 to $60 \%$ as a result of increases in fine sediment in the spawning substrate. Even if survival in the stream was not $80 \%$ for a given substrate before increases in fine sediment occurred, the $20 \%$ reduction in embryo survival predicted by the equation should be close to the decrease in embryo survival in the stream. If embryo survival was actually $50 \%$ in the stream instead of $80 \%$, survival of steelhead embryos should still decrease by $20 \%$ as a result of a given increase in fine sediment.

Predicting the consequences of an increased deposition of fine sediment in spawning areas is an important application of our research. In watersheds affected by human activities (e.g., road-building), sediment transport models are sometimes used to predict changes in stream substrate size composition. Anticipated changes in the spawning substrate are usually expressed as changes in the percentages of specified particle size classes. Such predictions could be used in the equations presented here to forecast the effects of human activities on steelhead and chinook salmon embryo survival.

\section{ACKNOWLEDGMENTS}

Funding for our research was provided by the U.S. Forest Service Intermountain Forest and Range Experiment Station in Boise, Idaho, and the National Science Foundation.

\section{REFERENCES}

BAMS, R. A. 1969. Adaptations of sockeye salmon associated with incubation in stream gravels. Pages 71-87 in T. G. Northcote, editor. Symposium on salmon and trout in streams. Institute of Fisheries, University of British Columbia, Vancouver, British Columbia, Canada.

BJoRnN,T.C. 1969. Embryo survival and emergence studies. Salmon and Steelhead Investigations, Job Completion Report, Project F-49-R-7. Idaho Department of Fish and Game, Boise, Idaho, USA. 
Cederholm, C. J., L. M. Lewis, and E. 0. Salo. 1981.Cumulative effects of logging road sediment on salmonid populations in the Clearwater River, Jefferson County, Washington. Pages 38-74 in State of Washington Water Research Center, editor. Salmon-spawning gravel: a renewable resource in the Pacific Northwest? Report 39, State of Washington Water Research Center, Washington State University, Pullman, Washington, USA.

Cederholm, C. J., W. J. Scarlett, AND E. 0. SALO. 1977. Salmonid spawning gravel composition data summary from the Clearwater River and its tributaries, Jefferson County. Washington, 1972-1976. University of Washington, Fisheries Research Institute Circular 77-1, Seattle, Washington, USA.

Cooper, A. C. 1965. The effect of transported stream sediments on the survival of sockeye and pink salmon eggs and alevins. International Pacific Salmon Fisheries Commission Bulletin 18.

Cordone, A. J., AND D. W. Kelley. 1961. The influence of inorganic sediment on the aquatic life of streams. California Fish and Game 47:189-228.

GibBons, D. R., And E. 0. SALO. 1973. An annotated bibliography of the effects of logging on fish of the western United States and Canada. United States Forest Service Technical Report PNW10, Pacific Northwest Forest and Range Experiment Station, Portland, Oregon, USA.

HALL. J.D., AND R.L.L.ANTZ. 1969. Effects of logging on the habitat of coho salmon and cutthroat trout in coastal streams. Pages 355-375 in T. G North-cote, editor. Symposium on salmon and trout in streams. Institute of Fisheries, University of British Columbia, Vancouver, British Columbia, Canada.

Iwamoto, R. N., E. 0. Salo, M. A. MadeJ, and R. L. MCCOMAS. 1978. Sediment and water quality: a review of the literature including a suggested approach for water quality criteria. U.S. Environmental Protection Agency, EPA 910/9-78-048, Seattle, Washington, USA.

KoskJ, K. V. 1966. The survival of coho salmon (Oncorhynchus kisutch) from egg deposition to emergence in three Oregon coastal streams. Master's thesis, Oregon State University, Corvallis, Oregon, USA.
Koski, K. V. 1975. The survival and fitness of two stocks of chum salmon (Oncorhynchus keta) from egg deposition to emergence in a controlled stream environment at Big Beef Creek. Doctoral dissertation, University of Washington, Seattle, Washington, USA.

LEITRITZ, E., AND R. C. LEWIS. 1976. Trout and salmon culture (hatchery methods). California Department of Fish and Game, Fish Bulletin 164. California Department of Fish and Game, Sacramento, California, USA.

MCNEIL, W. J., AND W. H. AHNELL. 1964. Success of pink salmon spawning relative to size of spawning bed materials. U.S. Fish and Wildlife Service Special Scientific Report Fisheries 469.

PARKER, R. R. 1971. Size selective predation among juvenile salmonid fishes in a British Columbia inlet. Journal of the Fisheries Research Board of Canada 28:1503-1510.

PHILlips, R. W., R. L. LANTZ, E. W. Claire, AND J. R. MORING. 1975. Some effects of gravel mixtures on emergence of coho salmon and steelhead trout fry. Transactions of the American Fisheries Society 104:461-466.

PlatTS, W. S., M. A. SHIRAZI, AND D. H. LEWIS. 1979. Sediment panicle sizes used by salmon for spawning, and methods for evaluation. U.S. Environmental Protection Agency, EPA-600/379-043, Corvallis Environmental Research Laboratory. Corvallis, Oregon, USA.

SHEN,H.W. 1971. River mechanics. Volume I. Colorado State University Press, Fort Collins, Colorado, USA.

SHIRAZI, M. A., AND W. K. SEIM. 1979. A stream systems evaluation-an emphasis on spawning habitat for salmonids. U.S. Environmental Protection Agency, EPA-600/3-79-109, Corvallis Environmental Research Laboratory, Corvallis, Oregon, USA.

TAGART, J. V. 1976. The survival from egg deposition to emergence of coho salmon in the Clearwater River, Jefferson County, Washington. Master's thesis, University of Washington, Seattle, Washington, USA.

THOMAS, A. E., J. L. BANKS, AND D. C. GREENLAND. 1969. Effect of yolk sac absorption on the swimming ability of fall chinook salmon. Transactions of the American Fisheries Society 98:406-410. 